\title{
вмJ Global Health Adolescent health in the Sustainable Development Goal era: are we aligned for multisectoral action?
}

\author{
Asha George (D) , ${ }^{1}$ Tanya Jacobs, ${ }^{1}$ Rajani Ved, ${ }^{2}$ Troy Jacobs, ${ }^{3,4}$ \\ Kumanan Rasanathan, ${ }^{5}$ Shehla Abbas Zaidi (iD ${ }^{6}$
}

\begin{abstract}
To cite: George A, Jacobs T, Ved $\mathrm{R}$, et al. Adolescent health in the Sustainable Development Goal era: are we aligned for multisectoral action?BMJ Global Health 2021;6:e004448. doi:10.1136/ bmjgh-2020-004448
\end{abstract}

Handling editor Seye Abimbola

Received 17 November 2020 Revised 10 February 2021 Accepted 15 February 2021

Check for updates

(C) Author(s) (or their employer(s)) 2021. Re-use permitted under CC BY. Published by BMJ.

${ }^{1}$ School of Public Health, University of the Western Cape Faculty of Community and Health Sciences, Cape Town, Western Province, South Africa ${ }^{2}$ National Health Systems Resource Centre, New Delhi, Delhi, India

${ }^{3}$ Global Health Support Initiative III, Rockville, MD, USA

${ }^{4}$ The George Washington University School of Medicine and Health Sciences, Washington, District of Columbia, USA

${ }^{5}$ Health Systems Global member Phnom Penh, Cambodia ${ }^{6}$ Community Health Sciences, Aga Khan University Faculty of Health Sciences, Karachi, Pakistan

Correspondence to Professor Asha George; asgeorge@uwc.ac.za

\section{ABSTRACT}

Adolescents are an increasing proportion of low and middle-income country populations. Their coming of age is foundational for health behaviour, as well as social and productive citizenship. We mapped intervention areas for adolescent sexual and reproductive health, including HIV, mental health and violence prevention to sectors responsible for them using a framework that highlights settings, roles and alignment. Out of 11 intervention areas, health is the lead actor for one, and a possible lead actor for two other interventions depending on the implementation context. All other interventions take place outside of the health sector, with the health sector playing a range of bilateral, trilateral supporting roles or in several cases a minimal role. Alignment across the sectors varies from indivisible, enabling or reinforcing to the other extreme of constraining and counterproductive. Governance approaches are critical for brokering these varied relationships and interactions in multisectoral action for adolescent health, to understand the context of such change and to spark, sustain and steer it.

\section{INTRODUCTION}

There are just 10 years left to achieve the Sustainable Development Goals (SDGs), with political calls from the highest levels of the UN systems and member states calling for urgent action. ${ }^{1}$ While time is running out for everyone, progress is lagging behind for some groups more than others. For health, accelerating the rate of progress requires scaling up and sustaining effective health interventions, concurrently with improvements in underlying social, economic and environmental conditions that is, the social and structural determinants of health. ${ }^{2}$ The focus of such acceleration, as highlighted once again by the COVID-19 pandemic, must be on those most left behind. This includes adolescents. ${ }^{1}$

Despite being an increasing proportion of low and middle income country populations, adolescents remain a neglected group. ${ }^{3}$ Yet their coming of age is an important foundation for health behaviour, as well as social
Summary box

- The social determinants of health are key in addressing the multiple health burdens faced by adolescents, demanding a far more effective multisectoral response for health than seen to date.

- Out of 11 intervention areas mapped for adolescent health, health is the lead actor for one, and a possible lead actor for two other intervention areas depending on the implementation context.

- All other intervention areas for adolescent health take place outside of the health sector.

- Given the lack of alignment, governance approaches are critical for brokering these varied relationships and interactions in multisectoral action for adolescent health.

- This involves understanding the political context of such multisectoral action, in order to spark, sustain and steer the changes required.

and productive citizenship for decades to come, shaping our sustainable future. With increasing adolescent population size, the societal contribution adolescents may make is also an important 'demographic dividend' for countries.

Adolescents are diverse beings, living in dynamic contexts and facing unprecedented challenges, including a complex burden of disease encompassing diseases of multidimensional poverty and inequality, injuries and non-communicable diseases (NCDs). ${ }^{4}$ The social determinants of health are key in addressing these multiple health burdens, demanding a far more effective multisectoral response for health than seen to date. ${ }^{56}$ In this sense all the SDGs, underpin the health and well-being of adolescents, with actions that address poverty, gender inequality, education, criminal justice, housing and food security. This requires extensive work within and across sectors to ensure effective change for adolescents. ${ }^{7}$ But 
Table 1 Typology for evaluating roles in multisectoral collaboration for health adapted from Rasanathan et al ${ }^{28}$

\begin{tabular}{ll}
\hline Health role & Interpretation \\
\hline Lead & $\begin{array}{l}\text { Activity is part of the core mandate of health, collaboration with other sectors is essential for health to } \\
\text { deliver on its core mandate. }\end{array}$ \\
Bilateral/trilateral & $\begin{array}{l}\text { Collaboration is required between two or more sectors to coproduce benefits, manage risks and to } \\
\text { maximise health benefits. }\end{array}$ \\
$\begin{array}{l}\text { Supporting } \\
\text { Minimal }\end{array}$ & $\begin{array}{l}\text { Collaboration involves initiatives that tackle structural determinants driving health inequalities. } \\
\text { Other sector's core mandates have spill over effects for health. }\end{array}$ \\
\hline
\end{tabular}

do we understand the implications of what that means for Ministries of Health?

As part of the Countdown 2030 Drivers Technical Working Group, we reviewed the evidence base for adolescent health interventions ${ }^{8-13}$ by drawing from leading reports $^{314}$ and existing systematic reviews. By intervention, we mean actions that have a direct or indirect effect on health implemented as projects, programmes or policies. Given the breadth of adolescent health, we focused on three tracer health areas (sexual and reproductive health including HIV, mental health and violence prevention) that make up key aspects of the burden of disease for adolescents and that involve varied actors. We map who is responsible for implementing these interventions across seven areas that emerged from our analysis of the systematic reviews as distinct approaches and settings for adolescent health. Our analysis examines the settings, roles and alignments of different sectors to support multisectoral action for adolescent health within these tracer areas in the SDG era (tables 1 and 2). In doing so, our analysis aims to enable a more nuanced understanding of not only the synergies gained, but also the tensions and precariousness of multisectoral collaboration, and the approaches needed to overcome the challenges involved. ${ }^{1516}$ By taking stock of what is known and mapping the types of responses required, we flag the importance of not just technical responses but particularly those that take a governance approach to facilitate the different types of relationships and interactions involved in brokering multisectoral collaboration for adolescent health. ${ }^{17}$

\section{ADOLESCENT HEALTH: ARE WE ALIGNED FOR TRANSFORMATIVE ACTION?}

Out of the seven intervention approaches or settings mapped out by our reading of evidence reviews, health is the lead actor for one: the provision of adolescent friendly health services which occurs within health facilities (table 3). It is also a possible lead actor for individual and family based interventions depending on the implementation context. For example, clinical services ranging from therapeutic counselling and voluntary medical male circumcision are a core mandate of the health sector, where health has a lead role.

However, even the success of voluntary male adolescent medical circumcision rests not just on the clinical service provided, but also in how it is coordinated with the education sector, local government and communities often led by traditional leaders. In this sense the enabling context is coproduced with the health sector. Similarly, mental health interventions for adolescents at individual and family level are coproduced by health with social development, education and sports sectors.

In contrast, violence prevention measures that are aimed at individual adolescents, their families or social groups, are largely the core business of other sectors such as social development, police and education. While vocational training and community policing initiatives aimed at reducing community violence have positive spillover effects for health, health is usually a minimal actor in such endeavours. Similarly, control of tobacco and smoking in adolescents may rest with local government and education sectors, with little involvement of those in the health sector. $^{18}$

Table 2 Typology for evaluating alignment for multisectoral collaboration adapted from Nilsson et $a^{30}$

\begin{tabular}{ll}
\hline Alignment & Interpretation \\
\hline Indivisible & Inextricably linked to the achievement of another goal. \\
\hline Reinforcing & Aids the achievement of another goal. \\
\hline Enabling & Creates conditions that further another goal. \\
Neutral & No significant or negative interactions. \\
\hline Constraining & Limits options on another goal. \\
Counteracting & Clashes with another goal. \\
\hline Cancelling & Makes it impossible to reach another goal. \\
\hline
\end{tabular}



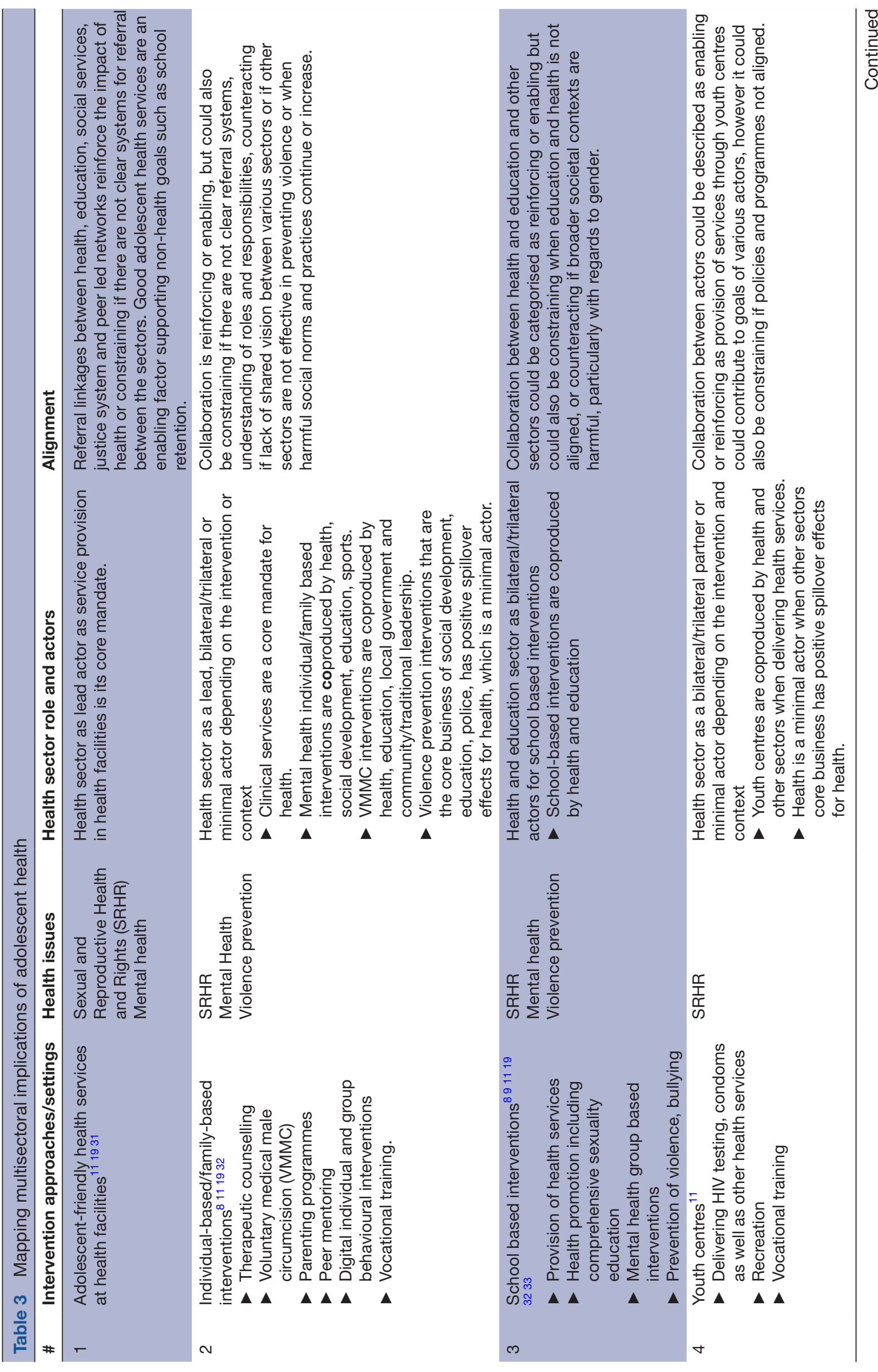


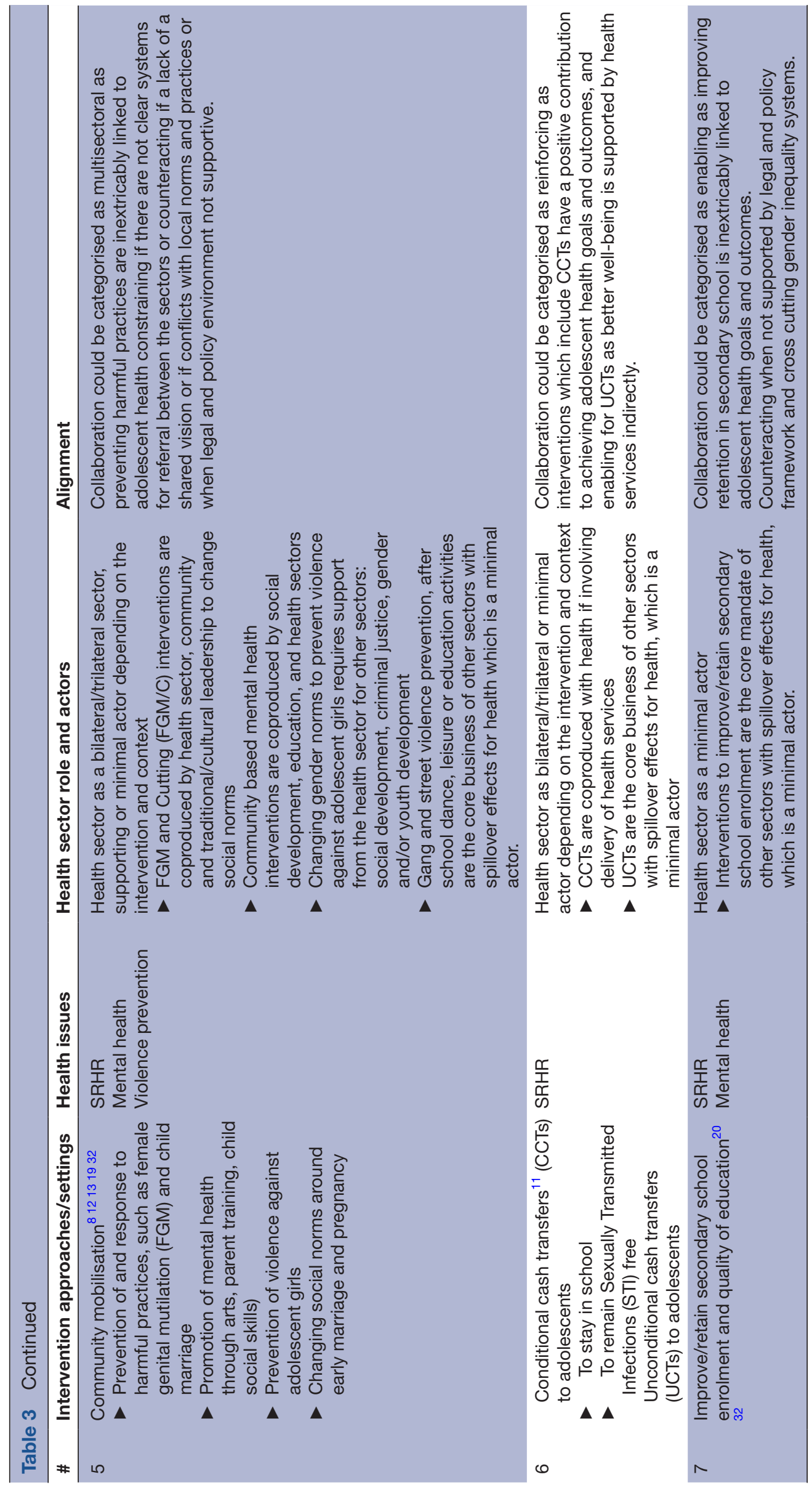


In four of the seven intervention approaches or settings (school based interventions, youth centres, community mobilisation and conditional cash transfers), health plays a bilateral or trilateral supporting role as they are involved in coproducing the outcomes. In these kinds of partnerships, roles and responsibilities need to be carefully negotiated, being mindful of the relationships, power and processes at play. However, as mentioned earlier, health may also play a minimal role if the activity is the core mandate of another sector, with benefits for the health sector that are largely through a spillover effect. For example, health benefits enormously from efforts to improve secondary school enrolment and quality of education, ${ }^{19}$ but plays a minimal role because these efforts are the core mandate of the education sector.

Not only does the role of the health sector vary significantly from lead, to supporting or minimal, the alignment across sectors is also varied and will be context specific. Across many of the intervention areas and settings, alignment between health and the other sectors is potentially reinforcing or enabling. For example, good adolescent health services support non-health goals such as school retention. ${ }^{3}$ Effective vocational training and social safety nets can reduce the risk of poverty and violence and therefore reduce morbidity and mortality from injuries for adolescents. ${ }^{20}$

However, alignment is not always positive. Even with school based health interventions, if referral and value systems are not aligned the sectors could be constraining one another or acting in counteracting ways. For example, policies that expel female adolescents from schools for being pregnant, run counter to ensuring inclusive and enabling support systems for such pregnant school-going adolescent mothers. While we did not find any systematic reviews that evaluated interventions that address the commercial marketing of unhealthy foods, tobacco or addictive substances to adolescents, this is clearly an area where health would be at odds with commercial interests.

\section{MOVING MULTISECTORAL ACTION FOR ADOLESCENT HEALTH FROM RHETORIC TO REALITY}

There is increasing documentation of what supports multisectoral action in health, most particularly from a governance lens. The latter is particularly important given the varied roles and alignment signalled above. We propose that there are four key insights from the governance literature on multisectoral action for health that are critical for unleashing the potential for multisectoral action for adolescent health. These include understanding contexts for change, triggers to spark change, capacities to sustain change and relationships to steer change. ${ }^{21}$

\section{Contexts for change}

Multisectoral action is an inherently political endeavour, and therefore, it is critical to understand the contexts in which changing the status quo in favour of multisectoral action for adolescent health takes place. It is critical to map out the different sectors involved, their own hierarchies or power configurations and the interests that drive them. These contextual factors may operate both formally and informally.

In South Africa, no less than six different sectors and related actors published at least 15 adolescent health policies between 2003 and 2018. ${ }^{22}$ Within that context the She Conquers campaign, addressing the structural drivers of adolescent girl's vulnerability to HIV, started with valuable political leverage from the former deputy President and now current President. It also sought to capitalise on aligning existing significant donor funding to HIV in South Africa. ${ }^{23}$ In Pakistan, the adolescent health agenda is mainly tied to reproductive health focusing on teen pregnancies and undernutrition, supported by scholarly work by a community of academics, clinical doctors and Non-governmental organisations (NGOs) working in maternal and child health. However, adolescent health has not been mainstreamed to other healthcare areas such as tobacco control, NCDs, mental health, missing the opportunity to be framed as a cross-cutting agenda. ${ }^{18}$

A key way of overcoming this complex terrain, including the different starting points involved, is to first understand how different sectors perceive multisectoral collaboration for adolescent health and whether a shared/aligned vision and accountability for common goals can be developed. This foundation is critical for building consensus around mutual goals or framing of the problem and corresponding solutions. In Indonesia, anaemia prevention in adolescent girls was addressed through schools by framing it as a problem affecting school performance and overall well-being, rather than a sexual and reproductive health issue. With this framing it sought buy-in from adolescent girls, teachers and parents as key stakeholders. Evidence on the burden of the problem, the effectiveness and safety of the approach convinced teachers and parents that while it required extra effort it was worthwhile to support the initiative. $^{24}$

\section{Triggers to spark change}

Changing business as usual takes tremendous effort. It is critical to take advantage of triggers or windows of opportunity that further heighten the urgency of multisectoral collaboration for adolescent health. With the She Conquers campaign key survey findings and research highlighting the transmission pathways and the effects of HIV on the economy and on jobs helped to mobilise political capital. ${ }^{23}$ In Malaysia, promotion of the human papilloma virus (HPV) in schools was triggered by the Ministry of Health responding to the World Health Assembly on cervical cancer. It convened an expert committee which reviewed experience from other countries and costeffectiveness studies in Malaysia. ${ }^{25}$ 


\section{Capacities to sustain change}

Even once mutual goals are arrived at and triggers motivate change, bureaucracies and systems need to have the capability to respond. This includes having designated human resources, management structures and leadership to support that change, with platforms and teams across sectors to implement change resourced with budgets. The ability to monitor multisectoral action for adolescent health and support continuous learning across the sectors involved is also critical.

In Malaysia, the initiative to address anaemia in adolescent girls built on existing platforms and chose a school based approach given the high rates of coverage of health interventions already achieved through this platform. Previously established operation rooms at national, state and district level for other health conditions became a key way to support the HPV immunisation programme. ${ }^{25}$ Similarly, in Indonesia the school health programme dates back to 1976 and was already endorsed by four ministries with established hierarchies, authorisations and scheduled meetings in place, making it a strong platform for rolling out HPV vaccines. ${ }^{24}$ Lessons in governing multisectoral action stress the importance of using existing structures, unless there is a compelling reason not to. ${ }^{26}$

In the USA, the network that galvanised attention and action on obesity in adolescents (Voices for Healthy Kids) found that investing in dedicated staff trained in stakeholder engagement was critical for fostering strategic relationships, strengthening partner commitments, facilitating fluid communication and building capacity for advocacy. A dedicated portal where grant recipients could access technical assistance providers helped facilitate linkages, but also document and track them. Funding for stakeholder organisations to lead workgroups or taskforces also supported broader coalition building and broader networking. ${ }^{27}$

\section{Relationships to steer change}

Given the complexity of the changes that must be brokered to sustain multisectoral action for adolescent health, it is critical for it to be anchored by relationships underlined by trust and respect to understand divergent needs and ways of working and competencies, including addressing conflicts of interest and managing trade-offs,${ }^{26}$ to put this into action. Individuals who are able to traverse the boundaries of sectors and institutions-'boundary spanners'-need to build alliances across agencies to problem solve challenges that are unforeseen. For these decisions to be steered in the right direction, they must not only be consultative across sectors, but also include the voice of adolescents as key agents in driving changes that ultimately benefit them.

In the USA, the Voices for Health Kids initiative recruited health equity and social justice leaders were to its strategic advisory committee. Community involvement was critical for goal setting, strategy selection, garnering broader support and once policies were passed, ensuring their implementation. Through this mobilisation community actors successfully sought resources from existing municipal funding streams. Documentation of success stories further sustained engagement. Overtime the forums to share and build mutual interests, supported by dedicated staff, and continuous learning from evaluations and feedback mechanisms, built relationships of trust. One stakeholder reflected that while messy, there is magic in the messy!". 27

Similarly in Malaysia's HPV school initiative, collaborative relationships evolved beyond the original contractual agreements to more a more nimble and effective ecosystem of partnerships between different parts of government, between government and pharma, between government and the media and between government and parents. Trust and credibility were built through evidence based planning and implementation, bolstered with strategic communication across all partners. ${ }^{25}$

In Indonesia, the success of the school based anaemia prevention programme also was due to relationships built between key actors, even when supported by established mechanisms for coordination. The informal networking supported data sharing and reporting, interest in progress and aided local decision making and accountability for procurement and other matters. Critically, adolescent girls were engaged through multiple phases in the initiative and played a key role in sustaining the initiative given the turnover among teachers. ${ }^{24}$

Ensuring youth engagement is not easy given their heterogeneity and the time and resources required to ensure participation from those most marginalised, as was found in South Africa's She Conquers campaign. Given that the performance of the campaign varied across provinces and districts, experiences and achievements from stronger locations where shared along with materials and lessons learnt at meetings fostering learning across settings. ${ }^{23}$ In Pakistan, there are also sharp disconnects between youth engagement initiatives and adolescent health initiatives. Youth engagement is politically championed by the highest level in Pakistan and supported by an increasing number of programmes many of which are managed by youth, however, adolescent health remains an area operationally confined to research and a few donor supported government programmes failing to draw on to youth engagement and discourse platforms. ${ }^{18}$

\section{CONCLUSION}

Governance matters and is a priority for the alignment of interventions in the SDG era. Correspondingly, both the technical and political aspects of 
multisectoral action for adolescent health must be prioritised. Looking across the evidence-based interventions that address adolescent health, it is clear from our mapping that multisectoral approaches are required for the majority of them although the exact nature of these approaches will vary across contexts. As a consequence, we can no longer treat adolescent health as being mainly the concern of the health sector; sectors ranging from education, social development, transport and communications, water and sanitation, and safety play vital roles. The challenges involved are precisely because health is not always the lead sector supporting multisectoral action for adolescent health in the SDG era and the alignment of sectors is not always positive.

Rasanathan et $a l^{28}$ notes that multisectoral collaboration for health is not equivalent to health imperialism. Conventional modes of command and control hierarchy ingrained in Ministries of Health may be particularly ill suited to facilitate multisectoral action for adolescent health involving both public and private health sectors and collaboration with other sectors. To move from rhetoric to reality, we outline key governance lessons critical for supporting multisectoral action by understanding (1) the political ecosystems or contexts for change, (2) triggers to spark change, (3) capacities to sustain change and (4) relationships to steer change. Further research is needed to enhance the understandings of the political ecosystems, mapping stakeholders and institutional architecture and power relations, identifying champions and alliances and reviewing and adapting the typologies noted above. ${ }^{29}$ Further, reviewing and building capacity at individual, organisational and systems level for distributed leadership and management and strengthening capacity for collaboration, as well as adolescent-responsive implementation, is needed going forward.

Rather than assume that Ministries of Health are natural leads for adolescent health, explicitly examining the governance implications may help sustain multisectoral action. It takes cognizance of the humility required in addressing the complexities involved and foregrounds the voice of adolescents given that their diversity and agency cannot continue to be ignored.

\section{Twitter Asha George @ashageorge72}

Contributors AG, TaJ and SAZ initially conceptualised the submission with additional inputs from TrJ, KR and RV. TaJ led the extraction of systematic reviews and reports. AG and TaJ developed the main table of analysis. AG drafted the submission. All authors provided inputs. AG finalised the submission.

Funding $A G$ is supported by the South African Research Chair's Initiative of the Department of Science and Technology and National Research Foundation of South Africa (Grant No 82769), the South African Medical Research Council and the Countdown 2030 project funded by the Bill \& Melinda Gates Foundation.

Disclaimer Any opinion, finding and conclusion or recommendation expressed in this material is that of the author and funders do not accept any liability in this regard.

Competing interests None declared.

Patient consent for publication Not required.

Provenance and peer review Not commissioned; externally peer reviewed.
Data availability statement Data for this paper included publicly available articles and documents and no additional data was generated. These articles and documents can be made available should that be required.

Open access This is an open access article distributed in accordance with the Creative Commons Attribution 4.0 Unported (CC BY 4.0) license, which permits others to copy, redistribute, remix, transform and build upon this work for any purpose, provided the original work is properly cited, a link to the licence is given, and indication of whether changes were made. See: https://creativecommons.org/ licenses/by/4.0/.

\section{ORCID iDs}

Asha George http://orcid.org/0000-0002-5968-1424

Shehla Abbas Zaidi http://orcid.org/0000-0001-7620-9247

\section{REFERENCES}

1 Sherr L, Cluver L, Desmond C, et al. A new vehicle to accelerate the un sustainable development goals. Lancet Glob Health 2020;8:e637-8.

2 Countdown to 2030 Collaboration. Countdown to 2030: tracking progress towards universal coverage for reproductive, maternal, newborn, and child health. Lancet 2018;391:1538-48.

3 Patton GC, Sawyer SM, Santelli JS, et al. Our future: a Lancet Commission on adolescent health and wellbeing. The Lancet 2016;387:2423-78.

4 Azzopardi PS, Hearps SJC, Francis KL, et al. Progress in adolescent health and wellbeing: tracking 12 headline indicators for 195 countries and territories, 1990-2016. Lancet 2019;393:1101-18.

5 Kuruvilla S, Hinton R, Boerma T, et al. Business not as usual: how multisectoral collaboration can promote transformative change for health and sustainable development. BMJ 2018;363:k4771.

6 Lo Forte C, Plesons M, Branson M, et al. What can the global movement to end child marriage learn from the implementation of other multi-sectoral initiatives? BMJ Glob Health 2019;4:e001739-7.

7 Clark H, Coll-Seck AM, Banerjee A. A future for the world's children? A WHO-UNICEF-Lancet Commission. Lancet 2020.

8 Salam RA, Das JK, Lassi ZS, et al. Adolescent health interventions: conclusions, evidence gaps, and research priorities. J Adolesc Health 2016;59:S88-92.

9 Salam RA, Faqqah A, Sajjad N, et al. Improving adolescent sexual and reproductive health: a systematic review of potential interventions. J Adolesc Health 2016:59:S11-28.

10 Das JK, Salam RA, Arshad A, et al. Interventions for adolescent substance abuse: an overview of systematic reviews. J Adolesc Health 2016;59:S61-75

11 Napierala Mavedzenge SM, Doyle AM, Ross DA. Hiv prevention in young people in sub-Saharan Africa: a systematic review. Journal of Adolescent Health 2011;49:568-86.

12 Ellsberg M, Ullman C, Blackwell A, et al. What works to prevent adolescent intimate partner and sexual violence? a global review of best practices. in: adolescent dating violence: theory, research, and prevention. San Diego, CA, US: Elsevier Academic Press, 2018: 381-414.

13 Toska E, Pantelic M, Meinck F, et al. Sex in the shadow of HIV: a systematic review of prevalence, risk factors, and interventions to reduce sexual risk-taking among HIV-positive adolescents and youth in sub-Saharan Africa. PLoS One 2017;12:e0178106.

14 WHO. Advocating for change for adolescents! a practical toolkit for young people to advocate for improved adolescent health and wellbeing, 2018.

15 Kim SS, Avula R, Ved R, et al. Understanding the role of intersectora convergence in the delivery of essential maternal and child nutrition interventions in Odisha, India: a qualitative study. BMC Public Health 2017;17:1-12.

16 Ved R, Menon P. Analyzing intersectoral convergence to improve child undernutrition in India development and application of a framework to examine policies in agriculture, health,. Int food policy Res insT, 2012. Available: http://www.ifpri.org/sites/default/files/ publications/ifpridp01208.pdf\%5Cnhttp://www.ifpri.org/publication/ analyzing-intersectoral-convergence-improve-child-undernutritionindia?print

17 Rasanathan K, Atkins V, Mwansambo C, et al. Governing multisectoral action for health in low-income and middle-income countries: an agenda for the way forward. BMJ Glob Health 2018;3:e000890.

18 Zaidi S, Memon Z, Najmi R, et al. Policy drivers for a multi-sector Adolescent Health response, Pakistan: The case of Nutrition \& Tobacco Control. Karachi, 2020. 
19 Patton GC, Sawyer SM, Santelli JS, et al. Our future: a Lancet Commission on adolescent health and wellbeing. Lancet 2016;387:2423-78.

20 Sheehan P, Sweeny K, Rasmussen B, et al. Building the foundations for sustainable development: a case for global investment in the capabilities of adolescents. Lancet 2017;390:1792-806.

21 George AS, Erchick DJ, Zubairu MM, et al. Sparking, supporting and steering change: grounding an accountability framework with viewpoints from Nigerian routine immunization and primary health care government officials. Health Policy Plan 2016;31:1326-32.

22 Jacobs T, DeJong M, George AS. Policy foundations for transformation a gender analysis of adolescent health policy documents in South Africa. Health Policy Plan.

23 Subedar H, Barnett S, Chaka T, et al. Tackling HIV by empowering adolescent girls and young women: a multisectoral, government led campaign in South Africa. BMJ 2018;363:k4585-11.

24 Roche ML, Bury L, Yusadiredja IN, et al. Adolescent girls' nutrition and prevention of anaemia: a school based multisectoral collaboration in Indonesia. BMJ 2018;363:k4541-6.

25 Buang SN, Ja'afar S, Pathmanathan I, et al. Human papillomavirus immunisation of adolescent girls: improving coverage through multisectoral collaboration in Malaysia. BMJ 2018;363:k4602-9.

26 Bennett S, Glandon D, Rasanathan K. Governing multisectoral action for health in low-income and middle-income countries: unpacking the problem and rising to the challenge. BMJ Glob Health 2018;3:e000880.

27 Callahan EA, Hollander M, McGhie DV, et al. Voices for healthy kids: a multisectoral collaboration to accelerate policy changes that promote healthy weight for all children and adolescents in the United States. BMJ 2018;363:k4763.

28 Rasanathan K, Bennett S, Atkins V, et al. Governing multisectoral action for health in low- and middle-income countries. PLoS Med 2017;14:e1002285.

29 Glandon D, Mondal S, Okeyo I, et al. Methodological gaps and opportunities for studying multisectoral collaboration for health in low- and middle-income countries. Health Policy Plan 2019;34:ii7-17.

30 Nilsson M, Griggs D, Visbeck M. Policy: map the interactions between sustainable development goals. Nature 2016;534:320-2.

31 Global Accelerated Action for the Health of Adolescents (AA-HA !). Guidance to support country implementation. Geneva, Switzerland, 2017.

32 World Health Organization. Global accelerated action for the health of adolescents (AA-HA!) guidance to support country implementation. Geneva: World Health Organization, 2017.

33 Mason-Jones AJ, Crisp C, Momberg M, et al. A systematic review of the role of school-based healthcare in adolescent sexual, reproductive, and mental health. Syst Rev 2012;1:1. 